\title{
The Path of College Foreign Language Teachers' Role Transition and Career Development under the Background of "Ideological and Political Theory Teaching in All Courses"
}

\author{
Lina Shi \\ Department of College English, Zhejiang Yuexiu University, Shaoxing, China \\ Email: 20072013@zyufl.edu.cn
}

How to cite this paper: Shi, L.N. (2021) The Path of College Foreign Language Teachers' Role Transition and Career Development under the Background of "Ideological and Political Theory Teaching in All Courses". Open Access Library Journal, 8: e7533.

https://doi.org/10.4236/oalib.1107533

Received: May 17, 2021

Accepted: July 6, 2021

Published: July 9, 2021

Copyright $\odot 2021$ by author(s) and Open Access Library Inc.

This work is licensed under the Creative Commons Attribution International License (CC BY 4.0).

http://creativecommons.org/licenses/by/4.0/

\begin{abstract}
"Ideological and political theory teaching in all courses" is an inevitable requirement of the reform of ideological and political education in colleges and universities. College classroom teaching contains abundant knowledge and ideological and political education, and an important part of the reform of education and teaching under the background of the "ideological and political theory teaching in all courses". Teachers are the key to the practical effect of "ideological and political theory teaching in all courses", therefore, this paper puts forward the new requirement for college foreign language teachers' career development and role transition under the background of "ideological and political theory teaching in all courses", and the practical dilemma faced by college foreign language teachers' career development under the new situation. Finally, it explores the innovative path of college foreign language teachers' development under the background of "ideological and political theory teaching in all courses".
\end{abstract}

\section{Subject Areas}

Language Education

\section{Keywords}

College Foreign Language Teachers, Career Development and Role Transition, Ideological and Political Theory Teaching in all Courses

\section{1. 引言}

习近平总书记在 2016 年全国高校思想政治工作会议上提出 “三全育人” 
的指导性意见, 根据会议精神, 思政教育不再专属于思想政治理论课教师和 政治辅导员, 包括外语教师在内的每一位高等教育工作者都是思政教育进课 堂的实践者和最终落实者, 肩负任务落地和理念创新双重使命。在日常外语 教学中融入价值观引领和思想政治教育, 以隐性教育的方法引导和培育学生 的价值观, 为新时期社会主义建设培养和输送合格人才成为大学外语思政育 人探索之路的工作目标。思政教育的核心是育人, 对思政教育尽快扎根于大 学外语课堂起关键作用的是教师。新时期广大教师如何理解时代赋予的新使 命、新挑战, 如何提高个人政治素养、提升教学能力是时代赋予广大外语教 师的新课题, 也是外语教师改变角色意识、重新定义自身价值、实现理论与 实践创新的原动力。

\section{2. 推动高校外语教师角色转换的主、客观因素}

课堂教学是教育的主阵地, 教学效果好坏关键在教师。长期以来有相当 数量的教师承袭了传统外语教学观念, 课堂上为学生输送语言学科知识, 锻 炼其语言使用能力; 课后搞搞科研写写文章, 站稳三尺讲台评上高级职称成 了很多外语教师亦步亦趋的人生规划。然而, 在新的时代背景下, 外语教学 不仅肩负着培养学生外语应用能力、跨文化交际能力的的工具性职能, 也承 担了丰富人文知识, 塑造和培育青年一代世界观、人生观、价值观的隐性使 命。可以说要实现高质量的外语思政教育, 摆在教育工作者面前的首要任务 是深刻理解思政教育进课堂的精神内核, 提高外语教师思政育人意识及思政 育人能力, 完善外语学科课程思政顶层设计, 走创新之路把 “立德树人” 充 分融入高校外语教学的方方面面, 将 “三全育人” 任务落到实处。

\section{1. 主观因素一一教师职业能力发展的内在驱动}

人文学科的核心是凸显人本价值, 注重人的全面发展。大学外语的人文 性价值在于它是学生了解并接纳文化多样性、培养跨文化交际能力的窗口。 如何引导学生以正确的立场看待不同国家之间文化和价值观差异; 如何以正 确的态度批判吸收不同思想观念并为我所用; 如何建立大学生本国文化自我 认感, 增强文化自信, 是高校外语教师开展外语思政教育研究的重要研究课 题。因此, 根据 “三全育人” 精神, 努力提高自身思政育人能力, 不直于自 身专业和学科限制, 勇于开拓创新外语教学方式方法是新时代背景下外语教 师谋求自身职业能力进步的内在推动力。

要出色完成时代和国家发展所赋予的艰巨任务, “立德树人” 的历史使 命感是推动广大外语教师深入钻研教学理论、不断精进自身业务能力的重要 内在驱动。教学与育人是教育不可分割的两个组成部分。所谓 “教” 即 “以 教化人” - - 通过教学活动教化学生, 使其掌握相关学科知识和专业素养获 取技能; 所谓 “育” 即 “以教育人”-—以在教学过程中培育、涵养学生的 精神世界, 塑造其正确的价值取向和人生理念。然而, “教” 可以通过各种 显性方式得以实现, “育” 则是隐性工程, 不能靠说教更不能靠考试, 需要 教师通过自己的身体力行潜移默化地影响学生, 于无形中塑造其世界观、人 生观、价值观。我国自古以来就有 “学高为师, 身正为范” 的育人理念, 教 
师不仅是课堂里传道授业解惑的良师, 教师的言行举止、思想观念的影响也 能延伸到课堂之外, 成为学生学习效仿的对象。因此, 教师除了做好教书本 职, 更要以高尚的道德情操、严谨的治学态度、朴实的生活作风感染学生; 以自身实际行动点亮学生心中对真善美的渴求, 帮助其成为有信仰、有追求、 有立场、有情怀的社会建设者。

\section{2. 客观因素——高校外语课程完善与发展的新方向}

大学生肩负着民族复兴国家富强的使命, 是宝贵的人才资源。大学生的 思想政治素养关系到党和国家的命运和前途, 对于推进党和国家事业发展具 有十分重要的意义。习近平总书记在全国高校思想政治工作会议上强调: “各 门课都要守好一段渠、种好责任田, 使各类课程与思想政治理论课同向而行, 形成协同效应。” 这是从国家层面对课程思政提出的明确要求。2 018 年, 《教 育部关于加快高水平本科教育全面提高人才培养能力的意见》要求把思政教 育贯穿高水平本科教育全过程, 强化课程思政和专业思政。2019年, 《教育 部关于深化本科教育教学改革全面提高人才培养质量的意见》要求把课程思 政建设作为落实立德树人根本任务的关键环节, 充分发掘各类课程和教学方 式中蕴含的思想政治教育资源。 2020 年, 《高等学校课程思政建设指导纲要》 将全面推进课程思政建设定位为落实立德树人根本任务的战略举措。《纲要》 进一步指出 “这一战略举措, 影响甚至决定着接班人问题, 影响甚至决定着 国家长治久安, 影响甚至决定着民族复兴和国家崛起” [1]。从 “强化课程思 政” 到 “关键环节” 再到 “战略举措”，教育部出台的一系列文件凸显了国 家对课程思政重要意义的认识过程, 对课程思政的定位和要求越来越高以至 于被写入国家政策规划纲领性文件[2]。《纲要》为广大教师开展学科思政教 育研究指明道路, 也为做深、做全 “三全育人” 提供顶层设计和制度保障。

大学外语课程思政建设需要明确 “为谁培养人, 培养什么人”, 需要以 全局性视角思考外语思政教育 “目的是什么, 目标是什么” ; 广大教育工作 者更要有前瞻视角, 思考如何培养掌握对外话语能力、能代表中国讲好中国 故事的新时期建设人才。要回答好这些问题, 各级各类高校需要深刻体会《纲 要》精神, 从外语学科可持续性发展的角度重新审视大学外语课程定位, 及 时调整外语学科建设侧重点, 新时期人才培养方案, 提升外语教师思政教学 能力; 同时以深化外语课程思政改革为契机理性看待自身不足补齐短板, 坚 定外语学科发展守正创新之路, 拓展思路打通学科壁垒将教学从课内延伸到 课外, 尝试 “外语 + 思政 + 专业 + 社会实践” 多方位、立体化外语教学 的新路子; 重视吸收、借鉴不同学科思政教育先进经验, 重视和发挥外语课 堂教学主渠道作用, 将立德树人融入日常教学, 努力实现 “全员、全程、全 方位育” 的 “三全育人” 大思政格局。

政策支持、学科建设、学生需求、教学理论完善与技术进步是驱动教师 主动谋求职业能力提升的客观驱动力。以扎实的外语教学能力结合过硬的思 政理论是外语教师开展高质量思政教学的不二法宝。“工欲善其事必先利其 器” , 高校外语教师首先要从理论层面主动学习以提高个人政治站位和道德 修养; 同时善于借鉴相关学科教学经验, 练就过硬的外语思政教学本领, 使 
思想意识、知识储备、师德师风等隐性实力同样经得起时代考验并能与时代 发展同向同行。

\section{3. “课程思政”理念下的高校外语教师角色全新定位}

在 “三全育人” 大思政格局指导下，“为谁培养人” ，“培养什么人”， “怎样培养人” 是新时期人才培养过程中必须明确的问题。一部分洞察敏锐 的教师能根据教学需要及时调整教学策略以适应时代发展趋势, 但也有相当 数量的教师固守传统课堂教学, 重技能轻人文, 重语言轻思政, 渐渐跟不上 外语课程建设的前进速度。因此, 以新观念、新思路看待新时期人才培养的 需求, 认真思考新时期高校外语教师在培养人才、服务社会方面的使命, 对 教师职能和角色进行重新定位, 是高校外语教师提升教学能力和思政育人能 力的重要突破口。

\section{1. 从思政教育的“被动适应者”转变为“引领者”}

当前中国特色社会主义建设进入了新阶段, 国家面临着诸多社会变革, “高校教师” 这一群体也因时代和社会赋予其更高的定位而面对更大的挑 战。一方面, 高校教师担负开拓研发前沿技术理论的任务, 扮演着社会进步 “引领者” 角色; 另一方面, 由于社会发展知识迭代速度不断加快, 一部分 长期埋头于课堂教学的教师存在着跟不上社会形势逐渐成为时代前进 “被动 适应者” 的潜在危机。

中国当前对外开放政策与国家发展战略需要我们在国际交往中为自己争 取更高的对外话语权, 日常对外交流中需要国人拥有更强的对外话语能力。 拥有高度文化自信, 能讲好中国故事、能在国际交往中树立中国大国形象是 新时期高层次人才培养工作的重要方向。作为高等教育的主要践行者, 高校 外语教师需要以 “引领者” 、“开拓者” 的心态迎难而上及时调整自我定位 才能适应社会进步满足学生个人发展新需求, 培育出对接国家发展战略需求 的人才，不幸负社会的期望，实现自身职业价值与理想的统一。

高质量的外语教学不仅传授学科知识也兼容思政育人。如何将思政元素 兼容并包进语言教学, 以 “软着陆” 方式实现大学外语思政教育是当前各级 各类高等教育机构和高校外语教师热烈讨论的话题。总体来看外语课程思政 建设还未形成完整的制度设计体系[3], 尚未系统性探讨特色院校和思政教育 相结合的理论与实践, 其整体设计、路径与载体、效果评价等方面的规范建 设和制度支撑相对薄弱, 导致教学改革动力不足 [4]。改革向来都不是一帆风 顺的, 守正创新与砥砺前行是大学外语思政发展完善之路的基调和底色。广 大教师要勇于突破学科和思维壁垒, 拓展视野不断更新丰富外语教育教学知 识储备, 在教学理念和教学方式方法上推陈出新, 寻找促进外语学科发展的 着力点、增长点, 通过积极尝试走出一条顺应时代潮流的外语高等教育发展 之路。在这条发展条道路上, 教师不仅用自己的敏锐洞察和前瞻意识引领学 科发展, 还有塑造学生思想道德世界的新理论和新方法论, 并通过教师之间、 院校之间的交流合作将学科建设与教师个人职业发展不断推向新高度。 


\section{2. 从知识的传授者转变为学习过程的参与者及学习共同体的 合作者}

在我国传统观念中传授知识是教师的主要职责, 外语教师的主要任务是 把教材内容整合起来讲授给学生, 同时提高学生语言实际运用水平和交际能 力。在全球化和互联网技术高速发展的新媒体时代, 学生获得知识的途径越 来越多样和快捷, 教师再也无法以 “知识的权威” 的身份出现。打破惯性思 维与学生组成学习共同体, 以积极而理性的心态面对这种局面是 “高校外语 教师” 全新角色定位。

学习共同体强调合作、互动与沟通, 学习者在学习体内共享观点、共享 知识, 履行自己的职责和义务, 学会尊重他人贡献, 开诚布公地发表个人意 见和观点, 在深入交流中形成成员之间的有机关联, 达成共识, 实现成员共 同进步 [5]。基于以上理念, 外语教师不仅充当外语课堂的组织者、外语学习 的指导者, 更要站在学生视角思考学生在外语学习过程中的实际需要, 成为 学生外语学习过程的合作者; 还要以问题为导向, 围绕学生知识需求编制授 课计划、设计教学过程; 引入互联网思维和产品思维将学生的学习需求作为 出发点, 找准痛点、难点进行有针对性的个性化教学, 积极寻找机会适时适 度地将外语教学与社会主义价值观渗透相结合, 塑造学生思想, 陪伴学生成 长, 帮助其成为立场坚定、思想成熟、外语能力过硬的新时期建设人才。

\section{3. 从思政教学执行者转变为思政教学系统性资源开发者}

长期以来受各种因素影响, 一部分教师在教育教学过程中习惯于按照教 学大纲制定的教学目标、教学内容、教学进度实施教学活动, 长期充当教学 计划 “执行者” 的角色, 对改进教学方式提升教学质量产生倦急感失去教学 创新热情。高校外语教师是接受过高层次教育和学术历练, 具有较高思辨和 分析能力以及高水平学科素养的高级人才, 具备对语言教学本质深层次思考 的能力以及一定程度的教育教学创新能力, 可以说高校外语教师有能力以研 发者的形象出现在教学领域最前沿, 结合实际教学洞察开发出适应日常外语 思政教学的新方法、新资源。

外语教学素材涉及历史、社会、宗教、艺术、思想等各种文化现象, 具 备丰富的人文价值; 而我国外语教学侧重点长期在语言技能培养上, 对人文 与道德培育元素利用尚不充分, 教学材料中有大量未被充分利用的内容。外 语教学材料不仅是知识的载体, 也是情感态度、社会文化价值与意识形态的 载体 [6]。基于外语学科人文元素丰富多样的特点, 当前外语课程的教育思政 资源尚有较大开发空间。在学科内部, 外语教师凭借长期教学观察和实践可 以通过理性分析和深度思考找到外语教学与思政教育的契合点和创新方向, 走出一条适合语言学科发展及外语教师自身职业提升的新路子; 在学科之间, 外语教师与思政专业教师也有充分合作机会构建 “外语教学 + 专业思政教 育” 模式; 此外, 外语教师相较于专业教师更大的优势在于外语课程覆盖面 广、教学时间跨度大, 有充足的时间对学生进行世界观塑造和价值观引领。 基于以上有利条件, 外语教师应该着力挖掘思政教育和外语教学协同育人的 潜力, 开发长期性、系统性教程, 通过研发新的教学方式和载体达到外语课 
程 “工具理性” 与 “价值理性” 并重, 实现教师从外语教学 “执行者” 到外 语思政资源 “开发者” 以及学生思政素养 “培育者” 的角色转换。

\section{4. 高校外语教师角色转换的策略}

\section{1. 提升政治素养和思政修养, 培养价值引领者角色意识}

青年人正处在人生观、价值观形成和确立的关键期, 高校要用符合时代 精神、对接国家发展战略的思政教育培养并影响青年学子, 引导他们扣好人 生中的 “第一粒扣子” [7], 可以说培育和践行社会主义核心价值观是当前思 政教育工作的重要使命。

教师肩负着培养合格社会建设人才的国家责任、政治责任和社会责任; 在 “课程思政” 理念的引领下, 广大外语教师要坚持教书与育人的统一, 树 立中国特色社会主义理想信念, 坚定马克思主义在意识形态的主导地位, 树 立政治意识、学生意识和质量意识, 坚守原则和底线把培养社会主义建设者 和接班人作为根本任务, 把培育和践行社会主义核心价值观贯穿于教学的全 过程。

随着信息技术和网络媒体的快速发展获取信息的途径、方式越来越便捷, 年青一代受到多元文化的冲击, 做价值判断时容易迷失方向。对于长期接触 外国思想和文化的外语教师而言保持自身正确的价值判断, 为学生提供正确 的价值观引导, 理性对待中外文化差异与教授学科知识一样都是教师的神圣 职责。习近平主席同北师大师生座谈时曾提到做好老师, 要有理想信念; 要 有道德情操; 要有扎实学识; 要有仁爱之心。坚定的政治立场、高尚的职业 道德水准、过硬的教学育人能力是高校教师教书育人能力的三大基石, 其中 坚定自身政治信念、提高自身政治站位更是广大教师实现自我人生价值和启 航职业发展新方向的压舱石。外语教师身处中西文化交流的连接点, 工作在 为学生介绍和了解西方文化现象及思想意识的最前沿, 长期接触快速成长中 的青年学子, 因此有责任也有义务将社会主义核心价值观教育融入外语课堂, 维护马克思主义在学生意识形态领域中无可感动的指导地位, 保持青年学子 对党的政治认同和情感认同; 培养新一代社会建设者振兴中华的宏伟志向, 培育和增强其民族自豪感和爱国情怀, 树立起建设大国形象和讲好中国故事 的观念; 调动大学生学习外语的积极性, 鼓励大学生关注社会、关心国家大 事, 引导大学生在完善自身文化素质的同时更多地参与实践活动, 不断提高 学生的社会责任感和使命感, 以上都是实现外语课堂思政教学纵深发展的努 力方向。

\section{2. 转变教学观念, 进一步发挥教师主观能动性}

社会发展带来了一系列新观念、新事物, 教师的教学观念也需要紧随时 代脚步不断更新: 从 “教学主导者”、“师长权威” 转变为学生成才之路的 “领路人”、“合作者” ; 多多听取学生内心的呼声和学习需求, 树立以学 习目标、学习需求为导向的教学观念, 打破固有身份和地位观念, 倡导师生 平等, 以此唤醒学生的自觉意识, 激发其学习外语、钻研学科知识的主观能 
动性。教师同样可以从自身出发践行 “身教重于言教” 的教学理念, 运用柔 性管理, 重视学生的内在精神需求, 给予学生更多正面评价, 注重师生之间 的深层情感交流, 通过建立师生共进的全员育人共同体, 不断提升高校外语 教学的思想政治教育的内涵和教学质量。

教学是动态发展的过程, 当下教学形式和技术手段不断进步, 新思路不 断涌现, 新教法层出不穷, 教师可采用合作探究、专题研讨、活动展示的教 学方式, 在课内课外同时构建起基于同辈学习理论的学习共同体, 将教师职 能由传递知识转变成激励学生思考, 从培养学生外语交际能力过渡到发展学 生外语思辨能力, 努力创造机会促进学生与学生之间、学生与教师之间的思 维碰撞和交流。此外, 教师的思维方式和治学理念也可在潜移默化中引导学 生树立正确的价值观、人生观、世界观, 正确对待各种文化现象和不同价值 观; 坚定立场、树立文化自信。这些举措不仅能使外语课程理性认识与人文 感化同在, 还能在共商共学中提高青年学子的认知水平, 增强认识问题和解 决问题的思维能力, 提高其解决问题的动手能力, 从而使课程的内容得以升 华, 工具价值与人文价值得以充分彰显。

\section{3. 培育创新精神, 走外语思政教育创新之路}

外语思政教育既是科研课题也是教改课题; 既要挖掘课程思政元素又不 能弱化学科与专业的难度和深度; 既不能脱离外语课程的性质特点又要深刻 理解学科教学与思政教学的价值内涵; 不仅要实现课程思政, 也要实现教师 思政、专业思政以保持课程元素发展的动态平衡。要打造高水平的外语思政 教学, 出路在于用宏大视角和前瞻性思维勇于改变思维定式和固有教学习惯, 不断思考探索适合学生心智模式以及当前国情的教学理论和教学方法, 善于 利用各种先进的数字技术和媒介渠道传授知识、传递价值观理念, 帮学生筑 牢外语知识和语言技能的坚实基础, 也为学生打造好精神世界的防火墙、承 重墙。

外语教师应当从日常教学实际出发, 培养大学生外语学习的基本媒介素 养和自我教育意识, 以多种多样的第二课堂教学形式作为依托充实外语思想 政治教育; 通过加快新旧教学载体的融合建设, 开展课堂教学、移动终端、 在线学习等不同媒介之间的自由切换, 将思政教育于无形之中融入语言教学 各个环节; 通过教师自觉示范为青年学生树立符合时代和社会发展的人生观、 价值观; 以课堂教学改良为起点, 深入体察、踏实研究, 逐步推动外语课程 思政教育改革, 从而获得教师个人素养、职业能力的进一步提高, 以此推进 学科建设的长足进步。

\section{5. 结语}

外语思政是在国家发展进入社会发展新阶段之时提出的新构想, 其理论 体系、评价机制尚在完善阶段。如何将思政教育融入外语教学过程的各环节, 怎样深入挖掘外语教学育人育德的隐性功能, 以何种手段实现润物于无声的 思政教育效果, 怎样有效测评思政教学效果, 中国外语教学如何走出一条有 中国特色的守正创新之路, 外语教师在科技进步日新月异的时代如何立足学 
科专业拥抱未来等等问题包括外语教师在内的广大外语教育工作者今后需要 深入思考和研究的课题。

教师是外语教学的实施主体, 是课堂教学的第一责任人, 更是学科发展 和教学质量提升的动力内核。文章从转变教学观念、转变教师角色的视角出 发, 分析了高校外语教师转变角色定位的主、客观驱动原因以及其在 “课程 思政” 时代背景下转换角色可能面临的挑战; 思考 “三全育人” 大思政格局 下高校外语教师如何通过转变角色达到修炼个人思政素养、打磨思政教学能 力的可行途径; 结合日常教学观察, 深入分析了外语教师在角色转变过程中 可能遇到的阻碍及其背后原因, 提出教师通过转换角色向内挖掘自身潜力提 升个人思政修养的具体策略。

“道阻且长, 行则将至” , 新时期广大外语教师在做好本职工作基础上 转变思想观念, 认真思考和研究时代赋予高校外语教师的新角色、新职能, 提高自身政治站位与德育意识, 通过完善个人能力带动思政教学与外语教学 的深入结合, 实现教学能力和思维认知双重提升, 不仅要上好外语课更要上 好有思政内涵的外语课, 最终为自己的职业发展道路翻开新篇章。

\section{Conflicts of Interest}

The author declares no conflicts of interest.

\section{References}

[1] 中华人民共和国教育部. 教育部关于印发《高等学校课程思政建设指导纲要》的 通知.

http://www.moe.gov.cn/srcsite/A08/s7056/202006/t20200603_462437.html, 2020-06-15

[2] 胡杰辉. 外语课程思政视角下的教学设计研究[J]. 中国外语, 2021(2): 53-59.

[3] 高德毅, 宗爱东. 课程思政: 有效发挥课堂育人主渠道作用的必然选择[J]. 思想 理论教育导刊, 2017(1): 31-34.

[4] 高燕. 课程思政建设的关键问题与解决路径[J]. 中国高等教育, 2017(15): 11-14.

[5] 刘正光, 岳曼曼. 转变观念、重构内容, 落实外语课程思政[J]. 外国语, 2020, 43(5): 21-29.

[6] 冯德正. 英语教学中的人文道德教育: 正面价值观的多模态语篇建构[J]. 外语界, 2015(5): 27-34.

[7] 夏文红, 何芳. 大学英语“课程思政”的使命担当[J]. 人民论坛, 2019(30): 108-109.

\section{Appendix (Abstract and Keywords in Chinese)}

“课程思政” 理念下高校外语教师角色转换与职业发展研究

摘要: 本研究以新时期推动高校外语教师转换角色的主、客观因素为切 入点, 结合教师授业、解惑、育人的职业特点深度思考 “课程思政” 进课堂 大背景下教师如何以角色转变带动教学能力提升, 从而实现外语思政教学质 量与教师职业发展共同进步的新途径。

关键词: 外语教师, 角色转换, 课程思政 